\title{
Ortega en búsqueda de la circunstancia liberal (1936-1955)
}

\author{
Ortega in Search of the Liberal Circumstance (1936-1955)
}

\author{
JUAN BAGUR TALTAVULL*
}

\begin{abstract}
Resumen: El artículo explica la evolución de la actitud de Ortega durante la Guerra Civil y el Franquismo, atribuyéndola a factores ideológicos y de percepción del contexto político. Buscó la circunstancia más propicia para la implantación del liberalismo, huyendo de planteamientos ideales que no tuvieran en cuenta la realidad sociopolítica. En este sentido, el anticomunismo le llevó a preferir a Franco durante la guerra, y el contexto internacional, a aprovechar durante la dictadura los "espacios de libertad" que le permitieron salvaguardar sus ideas sin comprometerse directamente con ella.
\end{abstract}

Palabras clave: Ortega, liberalismo, comunismo, utopía, circunstancia, exilio.

\begin{abstract}
The article explains the evolution of Ortega's attitude from the Civil War to the Francoism, relating it to ideological factors and the perception of the political context. He looked for the most favorable circumstance for the implementation of the Liberalism, fleeing from idealistic approaches that did not take into account the socio-political reality. In this sense, the anti-communism led him to prefer Franco during the war; and the international context, to take advantage of the "spaces of freedom" that allowed him to safeguard his ideas without committing himself directly to it.
\end{abstract}

Keywords: Ortega, Liberalism, Communism, Utopia, Circumstance, Exile.

\section{Introducción: el liberalismo orteguiano como oposición al utopismo}

En este artículo se presentarán los motivos de la evolución de la actitud de Ortega durante la Guerra Civil y el Franquismo. Según es conocido, el filósofo pasó desde el apoyo indirecto a Franco durante el conflicto, a un exilio que duró hasta 1945, seguido de la vuelta a España hasta su muerte en 1955. La aparente contradicción de estos tres momentos se explica desde la asunción por su parte de un objetivo: la defensa de un orden liberal en el que el anticomunismo es un elemento clave. Sin entrar en juicios morales, en este trabajo trataremos de comprender una actitud que filosóficamente se fundamenta a través del contenido que Ortega dio a dos nociones clave de su pensamiento: la de circunstancia, y la de utopía.

Recibido: 30/05/2019. Aceptado: 15/11/2019.

* Profesor Asociado de Historia Contemporánea en la Universidad CEU-Cardenal Herrera, especializado en la historia intelectual española y en el pensamiento de Ortega y Gasset. Sobre estos temas ha publicado trabajos como "El liberalismo de María Zambrano: de Ortega y Blas Zambrano a la Liga de Educación Social" (Bajo Palabra. Revista de Filosofía, n²2, 2019), "De la República socialista a la monarquía liberal: la evolución de la perspectiva nacionalizadora de Ortega en el contexto de la Gran Guerra" (en VVAA: La Gran Guerra en la España de Alfonso XIII, Sílex, 2019), o La idea de nación en la nueva política orteguiana: desarrollo y crisis del patriotismo fenomenológico (1909-1916) (Madrid, Ápeiron Ediciones, 2016). Email: juan-ba-89@hotmail.com 
Estas dos ideas se entienden precisamente desde la definición orteguiana del liberalismo. A pesar de la evolución de su pensamiento al respecto, un elemento permanente es el de considerar que su razón de ser fundamental es la limitación del poder. Algo que lo distingue de la democracia, referida a los orígenes del mismo; y que implica que, aunque no fuera lo ideal, en la práctica las dos nociones pudieran ir por separado ${ }^{1}$. A esto conduce otra constante del pensamiento orteguiano, que Pedro Cerezo $(1994,62)$ llamó la "política de base fenomenológica": desde que abandonó el neokantismo en 1914, hizo de la aceptación de los límites de la realidad un elemento fundamental de su posición política. El "yo soy yo y mi circunstancia" de 1914 es la clave de su pensamiento, hasta el punto de que en 1934 escribiría que "el resto de mi producción, que iba ser una batalla incesante contra el utopismo, está, pues, ya preformado en este mi primer libro" (Ortega, 2017b, 152).

En consecuencia, el liberalismo orteguiano fue siempre reformista, y se fundamentó en la expresión de que "solo debe ser lo que puede ser, y solo puede ser lo que se mueve dentro de las condiciones de lo que es" (Ortega, 2012, 487): planteaba que para limitar el poder era fundamental partir de las alternativas reales de cada momento, desechando construcciones ideales. En este sentido, escribe de Haro $(2008,95)$ que el proyecto que desarrolló era el de una "política realista o de realización de condición fenomenológica", que pretendía construir una España vertebrada y vital. Es la lógica que hay detrás de su apoyo al Partido Reformista en 1914, al republicanismo conservador de Maura en 1932, y, por los motivos que veremos, a Franco durante la Guerra Civil.

También es la actitud que se encuentra detrás de su firme oposición al comunismo. Ortega había sido socialista hasta el contexto de 1914, e incluso durante la II República defendió la labor del PSOE. Pero su socialismo fue siempre aristocrático, ético, y nacional; considerándolo un ideal que podía servir a las minorías selectas para vertebrar a la sociedad, integrando a los obreros en la nación ${ }^{2}$. Era un proyecto liberal y humanista, cercano al de Julián Besteiro y alejado del de Largo Caballero (López Frías, 1985, 109). Por ello, la "bolchevización" del PSOE durante la II República no hizo sino alejarle todavía más del socialismo español, considerándolo más cercano al comunismo que al liberalismo nacional.

En este marco, el comunismo - que prefería llamar bolchevismo- y el socialismo antiliberal eran definidos como paradigma de la rebelión de las masas. Ya en España invertebrada (1922) dedicó un capítulo al "sindicalismo", con el que se refería a los movimientos obreros particularistas. Según su pensamiento, una sociedad moderna debía estar nacionalizada, esto es, integrados todos sus miembros y clases en un proyecto sugestivo de vida en común. Como los nacionalismos periféricos, el bolchevismo era antinacional por su condición exclusivista. En La rebelión de las masas (1930) Ortega (2017a, 431) profundizaría en esta lectura, hablando del bolchevismo -y el fascismo-, como paradigma de la regresión anti-

1 Ortega (2012,541) expuso esta tesis en "Notas del vago estío" (1927), y la mantuvo en textos de los años cuarenta y cincuenta. Historia como sistema y Del Imperio romano (1941) pueden entenderse desde esta clave, y por tanto como una crítica larvada al Franquismo, pues entonces Ortega ya se había distanciado de él. Así lo hizo la revista Time al reseñar su traducción al inglés, provocando la indignación de $A B C$ (11 de junio de 1946).

2 El proyecto socialista de Ortega en torno a 1914 es definido por De Haro $(2008,110)$ como "un socialismo no utópico ni abstracto y encabezado por una minoría de cabezas claras", que fundamentaría una "gran comunidad espiritual de trabajadores libres" que buscarían, junto con lo material, "el sentido (o logos) de lo que les rodea para salvarse a sí mismos de su propio naufragio vital". 
liberal a la que conducía el hombre-masa. En el libro original, que comenzó a escribir en 1927, mostraba mayor temor por el fascismo. Pero no así en el "Prólogo para franceses" de 1937, ni en el "Epílogo para ingleses" de 1938. Entre medias, la experiencia republicana y de la Guerra Civil había modificado su percepción.

\section{Ortega durante la Guerra Civil}

Ortega había sido uno de los principales impulsores de la II República. Pero pronto se decepcionó con ella, debido a que consideraba que había caído en el mismo error que la Restauración: el particularismo político y social. Desarrolló esta visión desde 1931, y la mantenía a la altura de 1935. En esta fecha, según rememoraría María Zambrano (2011, 170-176), estaba "cada día más ensimismado y aún angustiado" porque no veía sino "el hermetismo creciente del ánimo de los españoles". Por ello, fraguó el plan de publicar un artículo que removería la opinión pública. Pero alguien filtró la noticia, y el filósofo decidió no actuar porque consideraba que el efecto sorpresa era clave del éxito. Inauguró así una actitud que aparecería durante la guerra, consistente en renunciar a actuaciones públicas que consideraba inútiles.

Acontecimientos como el exclusivismo religioso de la CEDA, la huelga revolucionaria de 1934, o la creciente violencia desde 1936, fueron vistos por Ortega como ejemplo del particularismo que venía denunciando desde hacía años. El estallido de la guerra entre las dos Españas era su culmen, y por ello no podía comprometerse con entusiasmo con ninguno de los dos bandos. Sin embargo, consideró que la opción por el bando franquista era un mal menor. No solamente porque su teoría política fuera más compatible con alguna de sus facciones, sino también como consecuencia de factores personales: sus hijos combatieron con las tropas de Franco, y personas que habían sido importantes en su biografía política -como Melquíades Álvarez o Manuel Rico Avello- fueron asesinadas (Gracia, 2014, 518). Él mismo firmó un manifiesto pro-republicano bajo amenazas, en unos momentos en los que el presidente José Giral tomaba la polémica decisión de armar a los milicianos: con este hecho, la acción directa, también analizada en España invertebrada, llegaba a su máxima expresión a través del particularismo obrero. La percepción orteguiana era que la rebelión de las masas estaba materializándose en su versión más violenta en el Madrid republicano.

El que la clave interpretativa del libro de 1922 estaba plenamente en su percepción, lo demuestra una carta que mandó a la Condesa de Yebes (10 de abril de 1938) a los dos años del inicio del conflicto. En ella aludía a un discurso de Ramón Serrano Suñer, que tildaba de "excelente" y del que destacaba que "sin ocultarlo dos tercios del discurso proceden de España invertebrada". En este discurso, el cuñado de Franco hablaba efectivamente de crear un Estado basado en la "selección de los mejores", y también de cumplir el "destino" de España desde la integración de todas las clases de la nación. Además, apostaba por sustituir al Estado liberal por otro autoritario, y exaltaba el catolicismo como elemento esencial de la identidad española (Azul, 3 de abril de 1938).

Este apoyo decidido de Ortega a Franco -en la carta, además, señala que no le cabe la menor duda de que esa "excelente" intención de Serrano Suñer es de acuerdo con "el de más arriba"-, se explica por su anticomunismo. Anticomunismo que, al contrario del de Franco y su cuñado, no se basaba en el catolicismo sino en el liberalismo; según puede deducirse 
de otras cartas. Por ejemplo, una que había escrito cuando al poco de estallar el conflicto la Comisión Depuradora Universitaria borró su nombre de la lista de profesores, tachándole de “contrarrevolucionario". Ortega (15 de octubre de 1936) no solamente no se lamentó por este apelativo y el suceso que provocó, sino que dijo a la Condesa de Yebes que "me satisface tan sabia determinación". Un año después, le escribió otra epístola (25 de julio de 1937) muy significativa porque resume el carácter del apoyo que en 1938 expresó hacia Serrano Suñer: "en la España blanca hay cada vez más orden si bien a costa de ir recayendo todo bajo el poder de las fuerzas más habituales". Es decir, apoyaba al bando franquista en sentido negativo: por su anticomunismo, y no por su defensa del nacionalcatolicismo.

Por otro lado, es importante tener presente que escribió esto desde el exilio, circunstancia que explica otro elemento de su interpretación de la Guerra Civil: la perspectiva europea. Mientras que la mirada que trascendía la frontera española llevó precisamente a personas como Azaña o Negrín a no entender por qué Gran Bretaña y Francia no intervinieron en favor de la República, para Ortega confirmaba una opinión que compartía con los conservadores de estos dos países. El fascismo y el nazismo, sin ser de su agrado, no le parecían tan peligrosos como el comunismo, y pensaba que había que supeditar todo a su derrota. Significativa es al respecto una epístola que mandó a Victoria Ocampo (21 de septiembre de 1936), en la que hablaba de una "discordia interna" que amenazaba con llevar a la guerra civil a Francia, porque "el comunismo ruso está haciendo su máximo esfuerzo -tal vez su esfuerzo postrero-, por descomponer toda Europa”. Desde esta convicción, y de nuevo muy en contra de lo que buscaban los republicanos, elogió la política de apaciguamiento de Chamberlain. Según otra carta a la Condesa de Yebes (11 de marzo de 1938), el líder británico hacía bien en cambiar su política ante Italia y Alemania, supeditando la política exterior británica a la derrota del comunismo, que tildaba de "causa inmediata de todos los desastres del continente".

Por tanto, Ortega se encuentra entre quienes redujeron la complejidad de los componentes del bando republicano a una revolución comunista, y desde su temor a la expansión de este movimiento se explica su apoyo al bando franquista; en el plano internacional, incluso a costa de aceptar el fascismo y el nazismo como aliados. Los documentos arriba expuestos son privados, pero coinciden en su intención con el "Epílogo para ingleses" (1937), escrito también desde su exilio parisino. Aquí vaticinaba la nueva articulación de Europa en torno a Estados liberales y totalitarios, asumiendo que "el «totalitarismo» salvará al «liberalismo», destiñendo sobre él, depurándolo, y gracias a ello veremos pronto a un nuevo liberalismo templar los regímenes autoritarios" (Ortega, 2017a, 528). Aunque había criticado el fascismo y el nazismo durante la década anterior, identificándolos con la rebelión del hombre-masa, en este texto hace patente que los comunistas eran quienes encarnaban la peor manifestación del proceso. Desde esta perspectiva dedicaba a los británicos un texto incluido en su obra magna, en lo que supone un claro respaldo al proyecto del Appeasement. De hecho, cuando Chamberlain y Hitler firmaron el Pacto de Múnich, escribió entusiasmado a Gregorio Marañón (30 de septiembre de 1938) porque lo veía como la confirmación de su profecía: "el acuerdo es un primer paso hacia lo que en mi Epílogo llamaba yo una «articulación provisoria» entre los Estados totalitarios y los liberales". Además, es relevante el hecho de que "En torno al pacifismo", incluido en el "Epílogo", estuviera escrito a partir de un artículo 
que antes intentó publicar, sin éxito, en el Times. En 1937 le había dado forma, después de contactar para ello con los propagandistas de Franco en Londres (Gracia, 2014, 536).

La defensa de un liberalismo anticomunista no tendría que haber llevado necesariamente a Ortega a apoyar al bando franquista, puesto que podría haberle vinculado a la "Tercera España". En el mismo año de la publicación del "Epílogo para ingleses", tuvo un interesante intercambio epistolar con Lorenzo Luzuriaga, donde éste hablaba de la creación de "un tercer partido, una minoría de gente inteligente y liberal". Consideraba que la victoria de cualquiera de los dos bandos en liza supondría "la desaparición para mucho tiempo en nuestro país del liberalismo", y por ello era menester seguir el modelo de Gran Bretaña (Luzuriaga a Ortega, 15 de julio de 1937). Allí gobernaba una coalición de conservadores y liberales, que proponía imitar en España desde la colaboración entre moderados de los dos bandos (Luzuriaga a Ortega, 1 de octubre de 1937). En estas cartas exponía que, como Ortega, veía en Gran Bretaña a la "nurse" de Europa. Era el modelo que, con su tradición parlamentaria, encarnaba los principios del liberalismo y la nacionalización que el filósofo defendía desde 1914. Pero Ortega, si bien podía simpatizar con el modelo británico, no aceptaba la vinculación con la “tercera España” porque lo consideraba utópico. De nuevo, el realismo político emanado de la aceptación de la circunstancia explica su actitud.

El filósofo contestó a Luzuriaga (2 de agosto de 1937) que su postura era la misma que ya había manifestado en una reunión en París, cuando expuso "mi extrañeza de que crea $\mathrm{Vd}$. y crean otros que podemos tener una intervención pública según las cosas están hoy; los que nos encontramos fuera de España”. Era factible, seguía, trabajar por uno de los dos bandos, pero carecía de sentido "pretender, hoy por hoy, representar una Tercera España". Afirmaba que "la cosa es deplorable pero a mi juicio, inevitable, por ahora", y sostenía que seguir la propuesta de Salvador de Madariaga era ridículo y contraproducente porque mostraría la "inanidad" de la "tercera posición". Madariaga había planteado, aconsejado por el Quai d’Orsay, que él mismo y Ortega lanzaran un manifiesto por la paz. El filósofo lo rechazó, también cuando Zubiri (15 de junio de 1937) le escribió intentando en vano hacerle cambiar de opinión.

En la carta a Luzuriaga (2 de agosto de 1937), Ortega sostenía que apostaba por el "triunfo de un liberalismo de tipo nuevo", y como él y Madariaga, sabía que eso era imposible con la existencia de las dos Españas. Pero a diferencia de ellos, hacía un análisis peculiar de la situación: "yo no creo que se trate de dos mitades sino más bien de esto: dos minorías extremas que luchan entre sí y el gran torso de la nación que por una determinada circunstancia se encuentra más cerca de Franco que de Valencia". Siendo más concreto, decía después que esta situación consistía en que "una parte de la clase obrera, alcoholizada por los eternos demagogos, ha querido hacer una revolución total". Incluso llegaba a escribir que la mayoría de los españoles simpatizaban con el liberalismo, cuyo modelo volvía a identificar con Inglaterra, y que la realidad española estaba falsificada en el extranjero.

Esta carta refleja una característica de Ortega: su anglofilia política. En muchas ocasiones, por ejemplo con ocasión de la Primera Guerra Mundial, había manifestado su admiración por el modelo político británico, según seguiría haciendo entre 1936 y 1939. Es significativo al respecto que en 1938 escribiera una carta a Winston Churchill ([marzo] de 1938). Aunque no llegó a mandarla, es conveniente aludir a ella porque allí expuso algunas ideas muy significativas. Para empezar, la escribía en agradecimiento por unas palabras que 
sobre España expuso el Primer Ministro en la Cámara de los Comunes. Con toda probabilidad, se refiere a la propuesta que lanzó a los europeos para aislar a Alemania y evitar una Guerra continental, señalando que España podría unirse porque "es cosa bien clara que el estilo vital de mis paisanos y la situación geopolítica de la península conspiran en una misma dirección": la amistad con Inglaterra. Ortega se había dado cuenta de lo equivocado que había estado al creer posible el apaciguamiento de Hitler, aunque esto en ningún modo implicara -como tampoco en Churchill- la aceptación del comunismo. Lo que había cambiado era la situación geoestratégica, que parecía caminar hacia un bloque liberal que terciara entre comunismo y nazismo/fascismo. Tal vez la razón por la que Ortega no llegó a enviar esta carta es que su intuición no se cumplió.

Por otro lado, comparaba a Winston Churchill con Edmund Burke, señalando que el segundo definió "el alma política inglesa” en su análisis sobre la Revolución francesa. Con sus Reflexiones de 1790 definió una tradición de pensamiento político basada en "temperar la rigidez de la «raison» con la elasticidad de la [ilegible] de la historia" (Ibid.). No en vano, el filósofo español había criticado en muchas ocasiones la Revolución francesa por ser un ejemplo de política utópica, basada en aplicar ideales sin tener en cuenta la circunstancia histórica. Si apreciaba el pensamiento de Burke, la actitud de Churhill, y la constitución de Inglaterra, es porque encarnaban las características de la Razón histórica ${ }^{3}$

\section{Del exilio al "semirregreso"}

Hasta el año 1938, Ortega creía que no existía alternativa entre el comunismo y un totalitarismo/autoritarismo conservador que a la larga daría pie al desarrollo del liberalismo; no solamente en España, sino también en una Europa donde intuía la creación de un bloque que opondría a Estados liberales y fascistas contra la URSS. Pero al estallar un año después la II Guerra Mundial, los acontecimientos fueron en una dirección muy distinta: liberales y fascistas se enfrentaron, y desde 1941, la Rusia comunista se alió con los primeros. El análisis de Ortega -lo que en 1938 llamó "profecía"- había fallado totalmente, y Franco no solamente no dio pie a la integración de sectores liberal-conservadores en su Gobierno, sino que se comprometió con el Eje nazi-fascista rodeándose de falangistas. No existió un equilibrio con el totalitarismo, sino una alineación con el mismo. Franco reivindicó abiertamente el concepto, y la Resolución 39 (1) de 1946 de la ONU declaró que el impuesto en España era un régimen totalitario cuyos orígenes se encontraban en la intervención de Alemania e Italia. Los países cuyo modelo liberal admiraba Ortega, quedaban enfrentados a la España dictatorial.

Esto le habría llevado a cambiar su percepción, como ocurrió con su amigo Gregorio Marañón. De manera temprana, le había dicho en una carta (8 de abril de 1940) que los hechos mostraban que la "lucha anticomunista, la llevan ahora, no los países dictatoriales,

3 En el Epílogo de 1937, Ortega (2017a, 512) había definido la Commonwealth como "el fenómeno jurídico más avanzado que se ha producido hasta la fecha en el planeta". Lo decía porque no era una construcción de la Razón utópica, sino basada en la experiencia histórica. Era la proyección del derecho consuetudinario al que, con el nombre de "poder público europeo", daría también una gran importancia en su apuesta por los Estados Unidos de Europa. En "Meditación de Europa" (1949), donde también expondría su admiración por Burke, Ortega $(2010,119)$ sostendría que solamente Inglaterra y Roma habían asumido este principio político fundamental. 
sino los liberales", y que por ello muchos republicanos españoles estaban abandonando el comunismo en favor de una "ilusión liberal". Esto lo escribía cuando el Pacto RibbentropMólotov de 1939 mantenía aliados a comunistas y nazis, y por tanto a Francia y Gran Bretaña en contra de ambos -y en guerra con los segundos. Pero la lógica de la afirmación se haría más evidente desde 1945, cuando efectivamente muchos republicanos del exilio formaron parte de proyectos culturales que se enmarcan en la Guerra Fría contra la URSS.

Sin embargo, pese al distanciamiento ideológico con la dictadura, Ortega volvió a España en 1945. No es casual que esperara hasta el final de la II Guerra Mundial, puesto que, tal y como había dicho en carta a Marañón (1 de enero de 1943), era necesario aguardar a "la conclusión de este juego a cara o cruz de la humanidad" para decidir el lugar de establecimiento. Recelaba, según se ve en esta epístola, de la deriva filo-fascista de la dictadura; y aunque se le acusó de complicidad con el régimen, hay que tener presente las condiciones y características de su retorno. Para empezar, no se integró en la vida oficial, a pesar de tener posibilidades para ello -Ruiz-Giménez, por ejemplo, le propuso como ministro de Educación-, y las intervenciones públicas que hizo se desarrollaron casi siempre desde iniciativas privadas. Además, realizó numerosos viajes por Europa y América, que incluyeron largas temporadas en Alemania, Suiza y Portugal; país este último donde mantuvo una residencia en Lisboa ${ }^{4}$. El suyo fue por tanto "un semirregreso, un regreso discreto e intermitente" (Fusi, 2017,16). Por otro lado, en la capital lusa se había asociado con el círculo monárquico de don Juan, en quien muchos exiliados vieron una alternativa viable frente a Franco (Gracia, 2014, 575).

Con todo, Ortega se relacionó con personas del régimen, aunque fuera a título personal, y tomó parte de algunas actuaciones que algunos interpretaron como muestra de apoyo a la España franquista. Por ejemplo, cuando inauguró el curso del Ateneo en 1947, con las conferencias que luego serían publicadas bajo el título "Introducción a Velázquez". Aunque no trató un tema político, el hecho de que aceptara esta intervención en un espacio de la cultura oficial podría verse como una señal de aceptación de la dictadura. Así lo daría a entender la revista falangista Destino (7 de junio de 1947), que refería este episodio como supuesta prueba de que Franco era un "gobernante de minorías".

Pero no volvió a España porque apoyara al dictador, sino por motivos vitales e intelectuales. En relación con lo primero, necesitaba anímicamente estar en España. Ya en 1936 le había dicho a Victoria Ocampo (carta, 21 de septiembre de 1936), que se sentía como una planta sin raíces, pues era de los que se veían "aniquilados" por no poder vivir sin ellas como las orquídeas. Además, volvía con 62 años, habiendo sido operado, y necesitando en los próximos años otras intervenciones médicas. No obstante, Julián Marías $(2008,275)$ recuerda que no retornó a España para morir: "vino a vivir -y vivió diez años- en ella y para ella, lleno de proyectos y de entusiasmos". Estos proyectos se entienden desde la razón intelectual de su regreso, esto es, a partir de la perspectiva que le llevó a ver que en España podía seguir defendiendo el liberalismo. De nuevo, la aceptación de la realidad y el rechazo del utopismo son la clave.

4 En 1947, Ortega habría dicho en una entrevista que el Gobierno de Franco no le molestaba, "pero yo vivo en Lisboa”. Aunque pueda darse por literal esta afirmación, pertenece no obstante a una entrevista que le hizo el mexicano Armando Chávez Camacho, sin tomar notas durante su transcurso. Alfonso Reyes (2016, 73-78) se la mandó a Ortega indignado, porque esta situación había provocado un malentendido en la relación entre ambos. 
El contexto histórico de la Postguerra mundial se entiende en el Viejo Continente desde dos factores: la amenaza del comunismo, y el movimiento de integración europea. España vivía por su condición de dictadura anticomunista entre dos aguas, rechazada en el segundo escenario, pero acogida en el primero. En cuanto a Ortega, siguió buscando la salvación de la circunstancia, esto es, huir de lo ideal buscando elementos de reforma; y lo hizo a través de los “espacios de libertad”. Así llamó Julián Marías, y con él Juan Pablo Fusi (2017), a iniciativas que permitieron salvaguardar la tradición liberal española, aprovechando los pocos resquicios que dejaba el Franquismo. Ello explica también que Ortega aceptara volver a España precisamente en 1945, cuando la fase totalitaria de la dictadura había dado paso a otra de carácter autoritario, ni mucho menos carente de represión o con burbujas democráticas, pero en la que la adaptación a una circunstancia mundial en la que el fascismo ya no tenía cabida, supuso que el poder no estuviera sometido a un partido único, sino disputado por facciones o familias - nacionalcatólicos, falangistas, carlistas, militares. Esto permitió cierta autonomía en algunos lugares, que aprovecharon Ortega y Julián Marías para fundar el Instituto de Humanidades en 1948. Según el programa anunciado en $A B C$ (18 de noviembre de 1948), llevaría a cabo tres tipos de actividades: "Investigaciones realizadas por pequeños equipos", centrada una en el método de las generaciones -dirigido por Marías-, y la otra en Goya -con Ortega y V. Sambricio. Lo segundo, "Cursos sobre temas asequibles" pero apoyados en ciencias generales -como uno sobre Toynbee, y otro sobre el método de las generaciones-; y por último, "coloquios-discusiones en que grupos de interlocutores competentes debatirán ante un reducido público de oyentes de temas de vivacidad e interés inmediatos".

El Instituto fue inaugurado por Ortega el 13 de diciembre, con una conferencia que criticaba A Study of History, de Arnold Toynbee. Según la reseña de $A B C$ (14 de diciembre de 1948), fue un auténtico éxito, con más de quinientas personas abarrotando el salón de actos del Círculo de la Unión Mercantil. Habían acudido médicos, catedráticos, aristócratas, banqueros, "estudiantes universitarios en número sobresaliente", y "hombres de la calle". El hecho de que un periódico como $A B C$ reseñara ampliamente, y en sentido positivo, todas las lecciones de Ortega, parece indicar que había encontrado en la España franquista un espacio para expresarse libremente. Así lo indica también el tratamiento que este diario dio a Ortega con ocasión del segundo curso del Instituto. ABC (22 de noviembre de 1949) ofreció la noticia con una amplia entrevista, que ocupaba la portada entera y parte de la siguiente página, con una gran fotografía del filósofo en el centro. El protagonista decía que el gran éxito del curso previo le infundió "ánimo para proseguir y responder" al entusiasta público. Había sido muy numeroso, a pesar de que existieron dificultades: renunciaron a la publicidad, se escogió un difícil día de la semana, y la matrícula era elevada. Lo había hecho de manera calculada, decía, para ver la reacción de los españoles. De estas declaraciones podemos deducir que se sentía animado, pues había encontrado un foro donde expresarse ante un público fiel y numeroso. Podía hablar de temas con un contenido político indirecto, como los que introdujo en "El hombre y la gente", y dar voz a intelectuales entre los que anunciaba a Dámaso Alonso, Luís Díez del Corral, Caro Baroja, o Julián Marías. Algunos de ellos también trataron temas de contenido político, como Díez del Corral al hablar del

5 En este y otros textos fundamenta lo que José Lasaga $(2017,62)$ llama "liberalismo comunitario". De hecho, un trabajo que lo compone, "Meditación del saludo", ha sido interpretado como una crítica al saludo fascista. 
régimen mixto -en lo que podemos ver una defensa del sentido histórico de los regímenes liberales basados en el equilibrio del poder, en la estela de las reflexiones orteguianas sobre el Imperio romano-, o Caro Baroja al tratar las "sociedades parciales españolas" -como también había hecho Ortega en los años veinte, exponiendo el fundamento geográfico de las regiones; aunque ahora frente a un Estado fuertemente centralista. Asistían a estos seminarios intelectuales como Alfonso García Valdecasas, Valentín Andrés Álvarez o Paulino Garragori (ABC, 30 de noviembre de 1949).

Pero a pesar de que las amplias reseñas de $A B C$ parezcan indicar un desarrollo normal del proyecto, la tolerancia era relativa. Según Marías, desde el principio encontraron la hostilidad del régimen, a lo que se unió la escasez de personas adecuadas para llevar a cabo la misión. En 1950 cesaron las actividades, aunque no porque Ortega se sintiera forzado a abandonar su proyecto. Marías $(2008,279-280)$ insiste en que su maestro quiso interrumpir los cursos, sin suspenderlos 6 , pero decidió viajar a Alemania. Un escenario fundamental, porque desde allí había pronunciado una de sus conferencias más notables en 1949: "De Europa Meditatio Quaedam". El año 1949 fue clave en la Guerra Fría: se fundó la República Popular China, la URSS desarrolló la bomba atómica y nació la OTAN. Además, se creaba el Consejo de Europa, en lo que algunos querían ver un primer paso hacia la federalización de los Estados del Viejo Continente. Ortega era un firme defensor de la unidad europea desde hacía décadas, y por ello no podía sino mirar con simpatía los movimientos europeístas de la Postguerra mundial. Pero en la práctica, la pretendida unidad europea se integraba en el bloque liderado por EEUU, y no era una tercera vía ante el comunismo de la URSS. Salvando las distancias, era tan poco realista como la "tercera España" de la Guerra Civil. Por ello, el propio filósofo formó parte de iniciativas en las que EEUU estuvo muy presente, destacando la creación del Instituto de Humanidades de Aspen, y la Universidad de Puerto Rico.

A Aspen (Colorado) fue invitado en 1949, con ocasión del bicentenario de Goethe. En su conferencia defendió las mismas ideas que ya había lanzado en Alemania, apostando por el citado pensador como paradigma de una Alemania liberal. Como en ocasiones anteriores -1908, o durante la Gran Guerra-, hablaba de dos Alemanias: una etnicista, que era la que había sido derrotada en 1945; y otra moderna. Mientras que en Europa y EEUU los vencedores seguían teniendo sospechas frente a los alemanes, Ortega $(2010,51)$ en sus conferencias de ambos lados del Atlántico los presentaba como ejemplo de reconstrucción de una federación de Estados-nación. No hablaba abiertamente de política, pero dejaba bien claro que estaba lejos de defender, como antiguamente, un liberalismo "atemperado", y optaba por el que encarnaban la República Federal Alemana y EEUU.

El Instituto de Aspen había sido fundado por un gran admirador del filósofo: el empresario de origen germano Walter Paepcke. Tenía intención de "salvar" la cultura alemana frente a los prejuicios que tenían sus compatriotas, pero también de hacer lo propio con EEUU y Occidente. En 1949 mandó al filósofo un interesante artículo que en 1945 había escrito Robert T. Hutchins -presidente entonces de la Universidad de Chicago- en el que hablaba

6 Ortega había terminado las doce lecciones del curso "El hombre y la gente”. Según reseñó $A B C$, aseguró que las interrumpía, pero no finalizaba. Se despidió del público "prometiéndole reanudar sus lecciones quizá esta primavera" ( $A B C, 23$ de febrero de 1950). 
del gran papel de las Universidades en la "atomic age”. Según él, era el de configurar una síntesis humanística que pudiera dotar de dirección moral a la técnica. Para lograrlo había que unir a los "leader thinkers of our time" en una "continuing conference" (Paepcke a Ortega, 5 de octubre de 1949). Por tanto, veía que el gran problema de la Guerra Fría no era la amenaza comunista como tal, sino la posibilidad de destrucción del mundo como consecuencia de la carrera armamentística. Ortega también había meditado mucho sobre la técnica $^{7}$, y era considerado uno de esos intelectuales que debían liderar la búsqueda de la solución. Paepcke se había entusiasmado al leer "Misión de la Universidad" -texto cuya tesis es, grosso modo, que esta institución es la única capaz de constituir el poder espiritual vertebrador de una sociedad-, y escribió al filósofo (2 de diciembre de 1949) para asegurarle que tanto él como Hutchins estaban totalmente de acuerdo con sus postulados.

Estas cartas de Paepcke nos dan pistas interesantes acerca de la intención de Ortega al fundar el Instituto de Humanidades de Madrid: si su interpretación era cierta, el filósofo no pretendía crear un simple centro de conferencias, sino una auténtica Universidad alternativa a la oficial de España. Pero entendiendo Universidad precisamente desde la concepción orteguiana: no tanto un centro oficial de investigación y enseñanza -aunque también debiera serlo en condiciones normales-, como un poder espiritual que fuera capaz de vertebrar a la sociedad, a través de la formación de su minoría selecta. Un elemento de continuidad en el pensamiento orteguiano es, desde sus primeros años como intelectual, la defensa de la Universidad en tanto que elemento nacionalizador. Leyendo a Renan desde joven, asumió esta interpretación que plasmaría en "Misión de la Universidad", y que hacía por tanto de la política directa algo secundario. Si era fiel a su teoría, Ortega durante el franquismo podía estar apartado de la política directa, pero no de la vida pública. Combinaba una acción en el segundo ámbito compatible con el silencio en lo primero, que se debe, como hemos visto anteriormente, a su creencia de que había que aceptar la circunstancia para poder actuar. Y esa circunstancia era un régimen que, por mucho que no fuera de su agrado, le ofrecía espacios de libertad que, creía, en un sistema comunista no tendría.

No obstante, no podía sino sentirse constreñido en Madrid. Y siendo defensor de unos Estados Unidos de Europa, consideraba que su labor en pro de esta entidad podía llevarla a cabo desde Alemania. Era un país que admiraba, en el que tenía gran popularidad y, sobretodo, en el que existía libertad política. Por ello quiso trasladar allí el Instituto de Humanidades: en 1953 se instaló en Múnich, financiado por la Fundación Ford después de haberse reunido con su presidente Robert Hutchins en Londres ${ }^{8}$, pero en 1954 volvió a España al sentirse enfermo (Gracia, 2014, 638). Este episodio refuerza dos argumentos ya señalados: primero, que Ortega había asumido plenamente su condición de intelectual puro, esto es, que

7 Ortega trató la relación entre técnica y guerra, fundamental en la Postguerra mundial, en diversos momentos. Es significativo que en 1954 diera una conferencia sobre este tema en la Reunión Europea de Empresarios celebrada en Torquay (Inglaterra). En ella se mostró optimista, según transcribe $A B C$ (24 de octubre de 1954), porque partía de la base de que el peligro de destrucción mundial podía implicar la renuncia a emplear la guerra. Se abría "la posibilidad de la muerte de la guerra, lo que sería algo completamente nuevo en la historia de la humanidad"; y con ello, la necesidad de buscar "un concepto de justicia social y principios sociales enteramente nuevos".

8 Según $A B C$ (5 de mayo de 1953), Ortega viajó a la capital inglesa para "participar en la articulación del plan educativo de la Institución Ford, como consejero de este nuevo organismo". Era la segunda reunión, después de la primera que había ocurrido en Chicago, y en ella Ortega figuraba junto con otros once sabios. 
incluso en un país con libertad política prefería vertebrar la sociedad desde la formación de las minorías selectas y no con la implicación política directa. Segundo, el factor fundamental que supone el estado vital de Ortega en estos años para entenderle: estaba enfermo y amaba España. Prefirió volver allí a pesar de haber logrado financiación de una Fundación tan importante como la Ford: la circunstancia existencial pesaba más que el proyecto intelectual.

Antes, había participado en la configuración de otra entidad importante: la Universidad de Puerto Rico. Tenía en común dos cosas con los Institutos: asumía las tesis de "Misión de la Universidad", y formaba parte de una red intelectual que se entiende desde la Guerra Fría. Su impulsor, y presidente desde 1942, fue Jaime Benítez. Era amigo de Hutchins, quien también tuvo un papel importante en la creación de esta entidad; pero especialmente era admirador de Ortega. Había viajado a Aspen para conocerle, y trató de atraerle para lograr lo que era el proyecto de su vida: reformar la Universidad desde las tesis orteguianas. En 1949 le dijo por carta (18 de mayo de 1949) que ya era una de las mayores influencias in absentia; y desde entonces quiso consolidar esta autoridad. Según contaría Benítez (1964, 113) más tarde, al conocerle le propuso que se trasladara a Puerto Rico, y consiguieron que la Fundación Ford les financiara.

Ortega pensó seriamente en trasladarse a la antigua colonia española, según se desprende de otras cartas. En una, Benítez (18 de mayo de 1949) hablaba de que estaban preparando las cosas para "tomar residencia en esta Isla y cátedra o sala de seminario en esta Universidad". Y en otra que unos meses después le mandó Ortega (12 de agosto de 1949), decía que acababa de hablar con Julián Marías acerca del "proyecto nuestro, es decir, que el Instituto de Humanidades vuele de Madrid a San Juan de Puerto Rico en febrero próximo". Para hacerlo posible, ya se había reunido con Berrien, de la Fundación Rockefeller. Solamente un año, parece ser, duró la ilusión del Instituto de Humanidades de Madrid, puesto que no tenían reparos en hablar de un traslado de este espacio a un lugar con verdadera libertad. Si no llegó a materializare este hecho, fue seguramente por lo que ya se ha indicado más arriba: el apego del filósofo a su patria, y su salud. Pero todavía en 1955 Benítez le insistió para que le visitara, y "Ortega contestó en principio entusiasmado". No indica si se trataba de un viaje corto o una estancia prolongada, como el exilio del que ya habían hablado. Pero probablemente sería algo más cercano a lo segundo, porque el puertorriqueño iba a desplazarse hasta Madrid para arreglar los detalles con la Fundación que en esta ocasión iba a financiarles, la Ford. Lo que ocurrió fue que el día en el que iba a viajar, le llegó la noticia de la muerte del filósofo (Benítez, 1964, 114).

No sabemos que habría ocurrido si Ortega no hubiera fallecido entonces, pero lo que es seguro es que la misión que desempeñó en España se circunscribió a salvar la cultura liberal aprovechando los estrechos espacios de libertad. Esta misma táctica siguió su discípulo Julián Marías, también gracias a la ayuda norteamericana. La Fundación Ford impulsó algunas de las iniciativas con las que mantuvo el legado del maestro: su presidente Waldemar Nielsen, que luego dirigiría el Instituto de Aspen, financió la Sociedad de Estudios y Publicaciones; y en 1960, el Seminario de Humanidades. Con esta entidad pretendía continuar la labor del Instituto, estudiando la estructura socio-histórica de España. Laín Entralgo o Aranguren se encuentran entre sus integrantes, evidenciando que los proyectos culturales de Ortega fueron importantes para forjar la red de la oposición intelectual del interior (Marías, 2008, 385 y 409). 


\section{Conclusión}

En las páginas anteriores se ha visto que existe una lógica dentro de la actuación de Ortega entre 1936 y 1955, a pesar de que existan tres fases que puedan invitar a pensar en una contradicción. Esta lógica está condicionada por el pensamiento político y filosófico de Ortega: por un lado, su apuesta por el liberalismo, y por otro, la convicción de que era necesario aceptar la circunstancia dada y rechazar la utopía para que el primero pudiera implantarse. Si la utopía es identificada siempre por Ortega con el comunismo, la circunstancia varió notablemente, y esto explica sus cambios de actitud.

En un primer momento, que se identifica con la Guerra Civil, Ortega creyó que sus ideales políticos estaban mejor representados en el bando franquista. Minusvaloró el peligro del totalitarismo fascista y llegó a apostar por una alianza de las democracias occidentales con Alemania e Italia. La II Guerra Mundial evidenció lo errado de esta posición, al aliarse las democracias liberales con el comunismo. Desde entonces, Ortega ya no aceptará una alianza con el fascismo, pero tampoco con el comunismo, y tendrá que moverse desde 1945 en un contexto con tres elementos: la dictadura de Franco, el proceso de integración europea, y la Guerra Fría. En esa circunstancia, vio que podía aprovechar los espacios que dejaba el Franquismo para llevar a cabo sus empresas culturales, fundando el Instituto de Humanidades. Pero sus ideales políticos estaban vinculados a Europa y Occidente, y por ello nunca llegó a identificarse del todo con España. Participó en la creación de otros Institutos en Alemania y Aspen -y una Universidad, la de Puerto Rico-, que se comprenden desde el conflicto intelectual de la Guerra Fría.

Por otro lado, se ha de tener presente que en la actitud de Ortega pesó mucho su situación personal, tanto física como anímica. No creía posible su felicidad fuera de España, y además, su salud en estos años evitó en más de una ocasión que viajara. Esto también explica su relación ambigua con España: hasta 1945 se mantuvo fuera, pero más que porque se hubiera exiliado, porque esperaba a la resolución de la II Guerra Mundial. Desde entonces, mantuvo su domicilio en Lisboa, pensó en establecerse en Puerto Rico, y vivió largas temporadas en países de Europa. En definitiva, el suyo fue, según podemos decir de modo similar a Juan Pablo Fusi, un "semiexilio" caracterizado por dos polos que le atraían hacia España: el apego a su patria y la convicción de que podía prestar un servicio a la cultura liberal. Para ello, aprovechó los pequeños espacios que dejaba una dictadura con la que solamente había compartido una cosa: su aversión al comunismo.

\section{Bibliografía}

Anónimo, «Conferencia de D. José Ortega y Gasset en la Reunión Europea de Empresarios», $A B C, 24$ de octubre de 1954.

Anónimo, «Creación de un Instituto de Humanidades», $A B C, 18$ de noviembre de 1948.

Anónimo, «Cursos de conferencias y otros actos culturales en Madrid», $A B C, 30$ de noviembre de 1949.

Anónimo, «El acto de anoche en el Coliseo, en Sevilla», Azul, 3 de abril de 1938.

Anónimo, «Final del cursillo de Ortega y Gasset», ABC, 23 de febrero de 1950.

Anónimo, «Franco, gobernante de minorías», Destino, 7 de junio de 1947. 
Anónimo, «La ignorancia de Time sobre los asuntos españoles», $A B C, 11$ de junio de 1946.

Anónimo, «Una nueva interpretación de la Historia universal», $A B C, 14$ de diciembre de 1948.

Benítez, J. (1963), Ética y estilo de la Universidad, Madrid, Aguilar.

Cerezo Galán, P. (1994), La voluntad de aventura: aproximamiento crítico al pensamiento de Ortega y Gasset, Barcelona: Ariel.

Haro Honrubia, A. de (2008), Élites y masas. Filosofía y política en la obra de José Ortega y Gasset, Madrid: Biblioteca Nueva.

Fusi, J.P., (2017), Espacios de libertad. La cultura española bajo el franquismo y la reinvención de la democracia (1960-1990), Barcelona: Galaxia Gutenberg.

Gracia, J. (2014), José Ortega y Gasset, Madrid: Santillana.

J.M., «Don José Ortega y Gasset en Inglaterra», $A B C, 5$ de mayo de 1953.

Lasaga Medina, J. (2017), «El liberalismo itinerante de Ortega y Gasset», en: Lasaga Medina, J. y López Vega, A. (eds.): Ortega y Marañón ante la crisis del liberalismo, Madrid: Editorial Cinca, pp. 13-78.

L.C., «Segundo año del "Instituto de Humanidades" de Ortega y Gasset», $A B C, 22$ de noviembre de 1949.

López Frías, F. (1985), Ética y política en torno al pensamiento de J. Ortega y Gasset, Barcelona: PPU.

Marías, J. (2008), Una vida presente: memorias, Madrid: Páginas de Espuma.

Ortega y Gasset, J. (2010), «[Apuntes para una Escuela de Humanidades en Estados Unidos]», en Obras Completas. Tomo X (1949-1955): obra póstuma e índices generales, Madrid: Taurus-Fundación José Ortega y Gasset, pp. 44-51.

Ortega y Gasset, J. (2010), «De Europa Meditatio Quaedam», en Obras Completas. Tomo X (1949-1955): obra póstuma e índices generales, Madrid: Taurus-Fundación José Ortega y Gasset, pp. 73-135.

Ortega y Gasset, J. (2012), «España invertebrada», en Obras completas. Tomo III (19171925), Madrid: Taurus-Fundación José Ortega y Gasset, pp. 421-512-

Ortega y Gasset, J. (2012), «Notas del vago estío», en Obras completas. Tomo III (19171925), Madrid: Taurus-Fundación José Ortega y Gasset, pp. 531-565.

Ortega y Gasset, J. (2017), «La rebelión de las masas», en Obras completas. Tomo IV (19261931), Madrid: Taurus-Fundación José Ortega y Gasset, pp. 349-528.

Ortega y Gasset, J. (2017), «Prólogo para alemanes», en Obras completas. Tomo IX (19391948): obra póstuma, Madrid: Taurus-Fundación José Ortega y Gasset, pp. 125-165.

Ortega y Gasset, J. (2004), «Socialización del hombre», en Obras completas. Tomo II (1916), Madrid: Taurus-Fundación José Ortega y Gasset, pp. 828-831.

Serrano Suñer, R., «El acto de anoche en el Coliseo, en Sevilla», Azul, 3 de abril de 1938. Zambrano, M. (2011), Escritos sobre Ortega. Edición, introducción y notas de Ricardo Tejada, Madrid: Trotta.

Epístolas (publicadas e inéditas)

Benítez, J., «Carta a José Ortega y Gasset. Puerto Rico, 18 de mayo de 1949», en Fundación Ortega-Marañón, Fondo JOG, C-4/2, ID: 5131. 
Zubiri, X., «Carta a José Ortega y Gasset. París, 15 de junio de 1937», en Fundación OrtegaMarañón, Fondo JOG, C-53/7, ID: 4134.

Luzuriaga, L., «Carta a José Ortega y Gasset. Glasgow, 15 de julio de 1937», en Fundación Ortega-Marañón, Fondo JOG, C-65/27ch, ID: 4033.

Luzuriaga, L., «Carta a José Ortega y Gasset. Glasgow, 1 de octubre de 1937», en Fundación Ortega-Marañón, Fondo JOG, C-65/27h, ID: 4036.

Ortega y Gasset, J., «Carta a Victoria Ocampo. Grenoble, 21 de septiembre de 1936», en Fundación Ortega-Marañón, Fondo JOG, CD-0/30, ID: 9727.

Ortega y Gasset, J., «Carta a Carmen, Condesa de Yebes. Grenoble, 15 de octubre de 1936», en Fundación Ortega-Marañón, Fondo JOG, CD-Y/14, ID: 10377.

Ortega y Gasset, J., «Carta a Carmen, Condesa de Yebes. Oegstgeest, 25 de julio de 1937», en Fundación Ortega-Marañón, Fondo JOG, CD-Y/18, ID: 10381.

Ortega y Gasset, J., «Carta a Lorenzo Luzuriaga. Oegstgeest, 2 de agosto de 1937», en Fundación Ortega-Marañón, Fondo JOG, CD-L/68, ID: 9389.

Ortega y Gasset, J., «Carta a Winston Churchill. [marzo] de 1938», en Fundación OrtegaMarañón, Fondo JOG, CD-D/2, ID:8882.

Ortega y Gasset, J., «Carta a Carmen, Condesa de Yebes. París, 11 de marzo de 1938», en Fundación Ortega-Marañón, Fondo JOG, CD-Y/23, ID: 10386.

Ortega y Gasset, J., «Carta a Carmen, Condesa de Yebes. París, 10 de abril de 1938», en Fundación Ortega-Marañón, Fondo JOG, CD-Y/25, ID: 10388.

Ortega y Gasset, J., «Carta a Gregorio Marañón. La Haya, 30 de septiembre de 1938», en Epistolario inédito: Marañón, Ortega, Unamuno. Edición de Antonio López Vega, Madrid, Espasa, 2008, pp. 199-201.

Ortega y Gasset, J., «Carta a Gregorio Marañón. Lisboa, 1 de enero de 1943», en Epistolario inédito: Marañón, Ortega, Unamuno. Edición de Antonio López Vega, Madrid, Espasa, 2008, pp. 210-211.

Ortega y Gasset, J., «Carta a Jaime Benítez. Lisboa, 12 de agosto de 1949», en Fundación Ortega-Marañón, Fondo JOG, CD-B/29, ID: 8595.

Marañón, G., «Carta a José Ortega y Gasset. París, 8 de abril de 1940», en Epistolario inédito: Marañón, Ortega, Unamuno. Edición de Antonio López Vega, Madrid, Espasa, 2008, pp. 266-268.

Paepcke, Walter., «Carta a José Ortega y Gasset. SL, 5 de octubre de 1949», en Fundación Ortega-Marañón, Fondo JOG, C-135/56, ID: 5506.

Paepcke, Walter., «Carta a José Ortega y Gasset. SL, 2 de diciembre de 1949», en Fundación Ortega-Marañón, Fondo JOG, C-135/60, ID: 10868.

Reyes, A. (2016), «Carta a José Ortega y Gasset. México, D.F., 17 de septiembre de 1947», Revista de Estudios Orteguianos, 33, pp. 69-81. 